
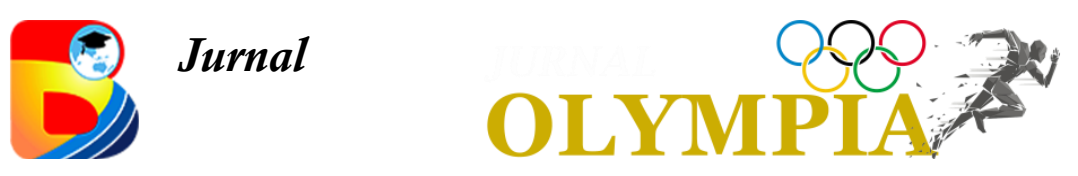

http://journal.binadarma.ac.id/index.php/olympia

\title{
Penerapan Metode Pasing Kaki Bagian Dalam melalui Permainan Gawang Segitiga untuk Meningkatkan Kualitas Passing Ekstrakurikuler Sepakbola MTSN 6 Sleman
}

\author{
Heri Nuryanta ${ }^{1}$, Antonius Tri Wibowo ${ }^{2}$ \\ Universitas Mercu Buana, Yogyakarta, Indonesia ${ }^{1,2}$
}

Info Artikel

Sejarah Artikel:

Diterima Desember 2021

Disetujui Februari 2021

Dipublikasikan Maret 2021

Keywords: sepakbola, permainan sepakbola gawang segitiga, keterampilan sepakbola

\begin{abstract}
Abstrak
Penelitian ini dilatarbelakangi oleh kemampuan passing siswa yang mengikuti kegiatan ekstrakurikuler di MTSN 6 Sleman masih rendah. Penelitian ini bertujuan untuk mengetahui kemampuan passing menggunakan gawang segitiga kemampuan passing siswa peserta ekstrakurikuler sepakbola di MTSN 6 Sleman. Dalam permainan ini dibatasi pada teknik passing kaki bagian dalam. Metode yang digunakan adalah penelitian tindakan kelas. Subjek penelitian ini adalah siswa ekstrakurikuler di MTSN 6 Sleman masih rendah dengan jumlah siswa 24 orang. Urutan kegiatan penelitian ini mencakup: (1) perencanaan, (2) pelaksanaan, (3) pengamatan, (4) refleksi. Pengumpulan datanya menggunakan RPP, lembar observasi dan dokumentasi. Analisis datanya menggunakan deskripsi presentase. Hasil penelitian menunjukkan bahwa pada siklus I rata-rata ketrampilan passing kaki bagian dalam sebesar 73, siswa yang mendapat nilai di atas 75 (KKM) sebanyak 13 siswa atau 54\%. Sedangkan pada siklus II rata-rata ketrampilan passing kaki bagian dalam sebesar 77, siswa yang mendapat nilai di atas 75 sebanyak 21 siswa atau 87\%. Sehingga hal itu sudah memenuhi target, yaitu $75 \%$. Hasil penelitian terdapat peningkatan dari beberapa indikator ketercapaian dalam setiap aspek, yaitu adanya peningkatan keaktifan siswa, kesungguhan dan keberanian siswa dalam mengikuti ekstrakurikuler sepak bola. Suasana siswa yang menyenangkan juga dapat memotivasi siswa untuk mengikuti praktek di lapangan
\end{abstract}

\begin{abstract}
This research is motivated by the passing ability of students who take part in extracurricular activities at MTSN 6 Sleman is still low. This study aims to determine the passing ability using a triangular goal the passing ability of students participating in extracurricular football at MTSN 6 Sleman. In this game, it is limited to the inner foot passing technique. The method used is classroom action research. The subjects of this research are extracurricular students at MTSN 6 Sleman which is still low with 24 students. The sequence of research activities includes: (1) planning, (2) implementation, (3) observation, (4)
\end{abstract}


reflection. The data collection uses lesson plans, observation sheets and documentation. Analysis of the data using a description of the percentage. The results showed that in the first cycle the average inner foot passing skill was 73, students who scored above 75 (KKM) were 13 students or $54 \%$. While in the second cycle the average inner foot passing skill was 77, students who scored above 75 were 21 students or $87 \%$. So that it has met the target, which is $75 \%$. The results of the study showed an increase in several indicators of achievement in every aspect, namely an increase in student activity, sincerity and courage of students in participating in extracurricular football. A pleasant student atmosphere can also motivate students to follow the practice in the field.

E-mail: 08hervaz@gmail.com ${ }^{1}$ antoniustriwibowo@mercubuana-yogya.ac.id ${ }^{2}$
ISSN 2656-5994(online) ISSN 2656-5986 (cetak)

\section{PENDAHULUAN}

Sepak bola adalah cabang olahraga yang paling digemari dan menarik perhatian masyarakat dunia saat ini. Banyaknya informasi tentang sepak bola yang disajikan oleh media elektronik dan media cetak adalah salah satu indikasi paling nyata dari pernyataan bahwa sepakbola adalah olahraga paling populer. Rekaman dan ulasan jalannya pertandingan di lapangan, profil pemain dan pelatih hingga stadiom tempat berlangsungnya pertandingan merupakan cerita menarik yang terjilid dalam ribuan media cetak, tersebar di seluruh negara, dibaca jutaan orang. Permainan sepakbola dikenal dan dimainkan bukan saja orang yang normal tanpa permaslahan kesehatan melainkan permainan sepakbola dimainkan juga oleh orang yang berkebutuhan khusus misalnya orang tuna daksa dan orang yang memiliki masalah sakit asma ringan (Wibowo \& Kushartanti, 2013). Oleh karena itu, sepakbola kini merupakan cabang olahraga paling populer dan diminati di dunia. Di Indonesia minat anak terhadap permainan sepakbola juga sangat tinggi. Khususnya di DIY sangat banyak pembinaan sepakbola dan salah satunya pembinaan sepakbola yang sangat latih yaitu MTSN 6 Sleman. Pembinaan siswa usia dini ini tentu sangat bagus untuk perkembangan sepakbola di Indonesia. Karena dengan adanya pembinaan ini dapat mempersiapkan pemain dari usia dini, memperkenalkan anak terhadap sepakbola.

Teknik dasar dalam sepakbola yang paling mendasar adalah menendang bola bahwa dalam melakukan tendangan dapat dilakukan dengan bermacam-macam bagian kaki antara kaki bagian dalam, kura-kura kaki bagian dalam, kura-kura penuh, ujung jari, kura-kura kaki sebela dalam dan dengan tumit. Setiap bagian kaki yang digunakan untuk menendang bola, menghasilkan tendangan yang berbeda

Passing merupakan teknik dasar yang paling sering digunakan dalam permainan sepakbola. Menurut Awang Roni (2017: 66) passing sebagai salah satu teknik dasar dalam 
permainan sepakbola yang harus dikuasai setiap pemain, karena ketrampilan tersebut membantu dalam membangun serangan ke arah pertahanan lawan serta dapat menciptakan peluang-peluang untuk terjadinya gol. Melihat betapa pentingnya penguasaan teknik dasar bermain sepakbola, maka bagi setiap pemain pemula (siswa sekolah) perlu dilatih dengan baik dan benar.

Rendahnya hasil belajar siswa bergantung pada proses pembelajaran yang dihadapi siswa. Dalam pembelajaran pendidikan jasmani khususnya sepakbola guru harus menguasai materi yang diajarkan selain itu guru juga harus dituntut kreatif untuk membuat bermacam-macam variasi pembelajaran yang bertujuan untuk mengurangi kebosenan dan kejenuhan siswa saat proses pembelajaran. Menurut Muhamat Rizal (2014: 560) tugas guru dalam rangka optimalisasi pembelajaran adalah sebagai fasilitator yang mampu mengembangkan kondisi belajar yang inovatif agar tercipta suasana belajar yang menyenangkan bagi siswa.

Penelitian yang relevan antara lain modifikasi sepak bola untuk penderita asma (Wibowo, 2013), program aktivitas permainan sirkuit anak usia dini (Taroreh, 2017), program aktivitas manipulatif berbasis kinestetik untuk anak 6 tahun (Taroreh \& Wijaya, 2020), permainan tradisional sebagai bahan ajar pembelajaran atletik Sekolah Dasar (Musiandi \& Taroreh, 2020), CBA (Culture Based Athletic) merupakan permainan pada pembelajaran atletik untuk melestarikan permainan tradisional Sumatera Selatan (Taroreh \& Satria, 2020), instrumen penilaian kinerja / autentik pembelajaran permainan bola voli Sekolah Dasar (Taroreh, 2012), model pembelajaran lari jarak pendek pada siswa SMP (Mayanto dkk., 2021), media Flash Card untuk pembelajaran lari siswa Sekolah Menengah Atas (Nahar \& Taroreh, 2020).

Berdasarkan observasi yang dilakukan di MTSN 6 Sleman dalam mengikuti pembelajaran permainan sepakbola pada saat melakukan passing masih sering melakukan kesalahan dan terkesan asal-asalan khususnya pada passing dengan kaki bagian dalam .Hasil observasi menunjukkan bahwa terdapat beberapa kendala yang dihadapi guru diantaranya variasi pembelajaran yang diberikan guru masih kurang serta media yang belum memadai seperti terbatasnya jumlah bola yang digunakan yaitu 2 buah bola. Dampak dari kurang ketersediaan media dan variasi pembelajaran oleh guru berpengaruh terhadap hasil belajar siswa.

Kreativitas guru dalam pembelajaran diharapkan sebagai salah satu cara untuk meningkatkan hasil belajar siswa. Melalui permainan gawang segitiga pembelajaran passing dengan kaki bagian dalam diharapkan dapat membantu siswa dalam meningkatkan hasil belajar dan membangkitkan semangat siswa untuk mengikuti pembelajaran.Alasan menggunakan permainan gawang segitiga pada pembelajaran passing kaki bagian dalam adalah membantu siswa mengarahkan bola serta ketepatan dalam mengukur target. 
Kegiatan ekstrakurikuler bertujuan mengembangkan potensi, pribadi dan prestasi peserta didik yang sehat jasmani dan rohani, bertaqwa kepada Tuhan Yang Maha Esa, memiliki kepedulian dan tanggung jawab terhadap lingkungan sosial, budaya dan alam sekitarnya.ekstrakurikuler di MTSN 6 Sleman yang memiliki banyak peminatnya. Hal ini di dukung adanya saran dan prasarana seperti lapangan, peralatan dan lainya.

Dari uraian di atas, dalam upaya untuk meningkatkan hasil belajar siswa, maka penulis tertarik untuk melakukan penelitian yang berjudul penerapan metode pasing kaki bagian dalam melalui permainan gawang segitiga untuk meningkatkan pasing ekstrakulikuler sepakbola MTSN 6 Sleman.

\section{METODE PENELITIAN}

Penelitian ini menggunakan metode penelitian tindakan kelas (PTK). Penelitian tindakan (action research) merupakan penelitian pada upaya pemecahan masalah atau perbaikan yang dirancang menggunakan metode penelitian tindakan (classroom action research) yang bersifat reflektif dan kolaboratif. Prosedur pelaksanaan penelitian tindakan berupa suatu siklus atau daur ulang berbentuk spiral (a spiral of steps) yang setiap langkahnya terdiri dari empat tahap, yaitu perencanaan, tindakan, observasi, dan refleksi (Wiraatmadja, 2009).

Arikunto (2006:2-3) mengemukakan bahwa penelitian tindakan kelas yaitu sebuah kegiatan penelitian yang dilakukan di kelas. Dengan menggabungkan batasan pengertian tiga kata inti, yaitu: (1) penelitian, (2) tindakan, (3) kelas, sehingga dapat disimpulkan bahwa penelitian tindakan kelas merupakan suatu pencermatan terhadap kegiatan belajar berupa suatu tindakan, yang sengaja dimunculkan dan terjadi dalam sebuah kelas secara bersama. Prosedur ini merupakan pedoman wajib dalam melakukan penelitian tindakan kelas untuk mengetahui hasil yang ingin dicapai peneliti guna evaluasi pembelajaran sehingga optimal. Secara garis besar di dalam penelitian tindakan kelas terdapat empat tahapan yang lazim dilalui yaitu, (1) perencanaan, (2) tindakan, (3) observasi, (4) refleksi (Arikunto, 2006: 20).

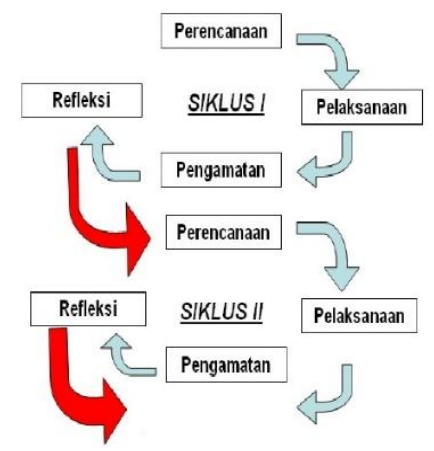

Gambar 1. Alur pelaksanaan penelitian tindakan kelas

Peneliti menggunakan rumus sebagai berikut:

$$
\mathrm{S}=\frac{\mathrm{R}}{\mathrm{N}} \mathrm{X} 100
$$

Keterangan

S : Nilai yang diharapkan (dicari)

$\mathrm{R}$ : Jumlah yang diperoleh siswa

$\mathrm{N}$ : Skor maksimal ideal

100 : Bilangan tetap

Untuk menentukan ketuntasan secara klasikal, menggunakan rumus sebagai berikut: 
$\mathrm{KB}=\frac{\text { Jumlah Siswa Tuntas }}{\text { Jumlah Keseluruhan Siswa }} \times 100$

Keterangan:

KB : Ketuntasan Belajar

Untuk menentukan ketuntasan praktek, maka dilakukan penskoran dan standar keberhasilan .dengan menggunakan sistem belajar tuntas (mastery learning), yaitu siswa berhasil jika mencapai $75 \%$ penguasaan materi . penguasaan penelitian ditentukan pada materi secara klasikal 75\%. Apabila pencapaian ketuntasan klasikal minimal $75 \%$ sudah tercapai, maka penelitian dihentikan.

\section{HASIL DAN PEMBAHASAN}

Berdasarkan prosedur penelitian tindakan kelas, dirancang dan dilaksanakan dengan sistematis dan terencana, maka penelitian ini dapat mengumpulkan data-data penelitian yang merupakan informasi penting hasil penelitian. Penerapan latihan teknik dasar passing kaki bagian dalam melalui permainan sepakbola gawang segitiga membawa dampak positif terhadap peningkatan ketrampilan siswa dalam melakukan teknik passing. Dari data hasil penelitian menunjukkan bahwa dari keseluruhan siswa MTSN 6 Sleman mengalami peningkatan nilai dan kenaikan presentase ketuntasan pada awal penelitian dapat diketahui bahwa ketrampilan siswa dalam melakukan teknik passing kaki bagian dalam masih sangat memprihatinkan. Berdasarkan hasil pengamatan terhadap teknik passing kaki bagian dalam pada prasiklus didapat hasil nilai rata-rata 65 dengan rincian 4 siswa sudah tuntas dan 20 siswa belum tuntas. Hal tersebut dikarenakan beberapa faktor diantaranya, masih banyak siswa yang menggunakan ujung jari untuk melakukan passing, pengambilan bola belum tepat ditengah-tengah bola dan selain itu pada saat menendang kaki tumpuan jauh dari samping bola.

Meskipun belum menunjukkan hasil yang memuaskan, pada siklus I telah terjadi peningkatan terhadap teknik passing kaki bagian dalam yaitu nilai rata-rata 73 dengan rincian 13 siswa sudah tuntas, dan 11 lainnya belum tuntas. Peningkatan teknik passing kaki bagian dalam pada siklus II menunjukkan perubahan yang cukup baik, hal ini dilihat dari hasil rata-rata siswa 77 , dengan rincian 21 siswa sudah dinyatakan tuntas dan 3 lainnya belum tuntas. Berdasarkan refleksi dari analisa data yang terkumpul maka hasil penelitian tindakan kelas terlihat bahwa pada akhir siklus ada peningkatan mutu pembelajaran passing kaki bagian dalam.

Tindakan penelitian yang dilakukan pada siklus I, ternyata belum memberikan dampak yang memuaskan dalam meningkatkan ketrampilan siswa dalam melakukan teknik passing kaki bagian dalam. Pemicu yang muncul dalam proses pembelajaran ini diantaranya, belum pahamnya siswa dalam melakukan teknik passing kaki bagian dalam yang baik dan benar, banyak siswa yang masih becanda.Meskipun belum menunjukkan hasil yang memuaskan namun pada siklus I telah 
menunjukkan adanya peningkatan dibandingkan dengan hasil dari prasiklus mengatasi masalah yang terjadi pada siklus I, proses pembelajaran di siklus II ini lebih berkonsentrasi terhadap penerapan permainan sepakbola gawang segitiga dan mengoreksi ketepatan melakukan passing untuk meningkatkan ketrampilan siswa dalam melakukan passing kaki bagian dalam. Pemberian motivasi dan latihan yang lebih bervariasi menimbulkan semangat dan suasana lebih kondusif dalam melakukan proses pembelajaran. Kemajuan siswa dalam proses pembelajaran ditandai dengan siswa lebih antusias dalam melakukan gerakan passing kaki bagian dalam.

Peningkatan ketrampilan pada siklus II menunjukkan perubahan yang cukup baik, dimana nilai rata-rata siswa 77 dengan rincian 21 siswa sudah tuntas dan 4 belum tuntas. Peningkatan ketrampilan melakukan passing kaki bagian dalam bila dibedakan antara siswa yang sering berlatih dan tidak, ternyata siswa yang sering latihan lebih cepat menyesuaikan dalam pembelajaran, faktor-faktor pendukung pelaksanaan gerakan komponen keberanian dan percaya diri serta siswa yang sering berlatih lebih sering bermain sepakbola. Sedangkan pada siswa yang jarang berlatih walaupun tingkat penguasaan teknik passing kaki bagian dalam belum begitu menguasai tetapi kesungguhan dan keinginan untuk mencoba begitu besar dan ingin bisa melakukan teknik passing kaki bagian dalam.

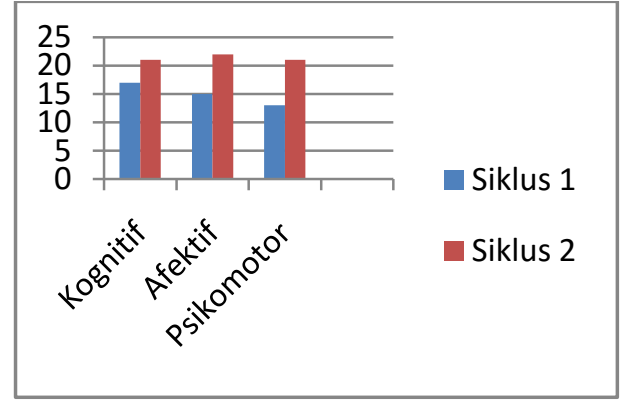

Gambar 1. Diagram Ketuntasan Hasil Belajar Siklus I dan Siklus II

Berdasarkan diagram ketuntasan hasil belajar pada siklus I dan siklus II menunjukkan peningkatan pada setiap aspeknya. Ketuntasan belajar aspek kognitif pada siklus I yaitu sebesar 17 atau $71 \%$, pada siklus II sebesar 21 atau $87 \%$. Ketuntasan belajar aspek afektif pada siklus I yaitu sebesar15 atau $63 \%$, pada siklus II sebesar 22 atau 92\%. Ketuntasan belajar aspek psikomotor pada siklus I yaitu sebesar 13 atau $54 \%$, pada siklus II sebesar 21 atau $87 \%$.

\section{SIMPULAN}

Berdasarkan hasil penelitian dan pembahasan yang telah diuraikan, dapat disimpulkan bahwa permainan sepakbola melalui gawang segitiga dapat meningkatkan ketrampilan passing kaki bagian dalam siswa MTSN 6 Sleman. Peningkatan ketrampilan passing kaki bagian dalam dapat dilihat dari nilai pada siklus I sampai siklus II. Pada siklus I nilai ketuntasannya adalah $66.6 \%$ dan pada siklus II menjadi $87 \%$.Nilai rata-rata ketrampilan passing kaki bagian dalam juga meningkat, yaitu pada siklus I adalah 70, pada siklus II menjadi 78 . Nilai rata-rata ketrampilan passing kaki bagian dalam juga meningkat, yaitu pada siklus I adalah 73, pada 
siklus II menjadi 77. Data tersebut menunjukkan peningkatan keterampilan passing kaki bagian dalam pra siklus sampai dengan siklus dua.

Berdasarkan hasil penelitian di atas dapat disimpulkan penelitian sudah berhasil dengan baik, sesuai kriteria ketuntasan minimal yang telah ditetapkan, dan sesuai yang diharapkan dengan tujuan pembelajaran yang menarik dan sangat mempengaruhi teknik passing kaki bagian dalam sehingga meningkatkan hasil belajar passing kaki bagian dalam melalui permainan gawang segitiga siswa MTSN 6 Sleman

\section{DAFTAR PUSTAKA}

Arikunto (2006). Penelitian Tindakan Kelas. Jakarta: Bumi Aksara.

Mayanto, Akis dkk. (2021). Model Pembelajaraan Jarak Pendek Pada Siswa Sekolah Menengah Pertama. Jurnal Kejaora (Kesehatan Jasmani Dan Olah Raga), 6(1), 114-120. https://doi.org/10.36526/kejaora.v6i1.11 74.

Musiandi, T., \& Taroreh, B. S. (2020). Pengembangan Pembelajaran Atletik Melalui Pendekatan Permainan Tradisional Sumatera Selatan. Jurnal Olympia, 2(1), 29-37. https://doi.org/10.33557/jurnalolympia.v $\underline{2 i 1.885}$.

Nahar, A., \& Taroreh, B. (2020). Pengembangan Model Pembelajaran Lari Melalui Media Flash Card di Sekolah Menengah Atas. Jurnal Olympia, 2(2), 34-41. Retrieved from http://journal.binadarma.ac.id/index.php/ olympia/article/view/1266.

Rizal, Muhamat. (2014). Peran Guru Kelas Dalam Menangani Kesulitan Belajar. Bandung: Alfabeta.
Roni, Awang Effendi. (2017). Meningkatkan Ketrampilan Passing Menggunakan Kaki Bagian Dalam Pada Permainan Sepakbola Menggunakan Metode Drill. Jurnal Pendidikan Olahraga, 6,65-74.

Taroreh, B. S. (2012). Model Performance Assesment of Learning Outcomes of Volleyhool Ball in Elementary School. Journal of Physical Education and Sports, $\quad 1(2), \quad 79-86$. https://doi.org/10.15294/JPES.V1I2.806.

Taroreh, B. S. (2017). Development Model Approach Through Exercise Kinesthetic Game Circuit for Children Ages 4-6 Years. JIPES - Journal of Indonesian Physical Education and Sport, 3(1), 41. https://doi.org/10.21009/JIPES.031.06.

Taroreh, B. S., \& Satria, M. H. (2020). Implementasi Permainan CBA pada Pembelajaran Atletik sebagai Solusi Alternatif Melestarikan Permainan Tradisional di Sumatera Selatan. Jurnal Curere, $4(1)$. https://doi.org/10.36764/jc.v4i1.348.

Taroreh, B. S., \& Wijaya, M. A. (2020). Program Aktivitas Fisik Manipulatif Berbasis Kinestetik Untuk Anak Usia 6 Tahun. Jurnal Penjakora, 7(1), 1-10. https://doi.org/10.23887/penjakora.v7i1.

Wibowo, A. T. (2016). Gaya Hidup, Kebugaran Jasmani, dan Konsentrasi Atlet Bolabasket Tim Satya Wacana Salatiga Menghadapi indonesian basketball league (IBL) 2017. Sportif, $2(2), 76-84$.

Wibowo, A., \& Kushartanti, W. (2013). Modifikasi Permainan Sepakbola bagi Siswa SMA Penderita Asma. Jurnal Keolahragaan, 1(2), 104-119. https://iournal.uny.ac.id/index.php/iolahr aga/article/view/2567/2121.

Wiriaatmadja, Rochiati. (2009). Metode Penelitian Tindakan Kelas. Bandung: PT Remaja Rosdakarya. 